\title{
Calibration of an all-sky camera for obtaining sky radiance at three wavelengths
}

\author{
R. Román ${ }^{1}$, M. Antón ${ }^{2,3}$, A. Cazorla ${ }^{2,3, *}$, A. de Miguel $^{1}$, F. J. Olmo ${ }^{2,3}$, J. Bilbao ${ }^{1}$, and L. Alados-Arboledas ${ }^{2,3}$ \\ ${ }^{1}$ Laboratorio de Atmósfera y Energía, Departamento de Física Aplicada, Universidad de Valladolid, C/ Dr. Mergelina s/n, \\ 47005 Valladolid, Spain \\ ${ }^{2}$ Centro Andaluz de Medio Ambiente (CEAMA), Av. del Mediterráneo s/n, 18006 Granada, Spain \\ ${ }^{3}$ Departamento de Física Aplicada, Universidad de Granada, Campus de Fuentenueva s/n, 18071 Granada, Spain \\ *now at: Department of Chemistry and Biochemistry, University of California, San Diego, 9500 Gilman Drive La Jolla, \\ California 92093, USA
}

Correspondence to: R. Román (robertor@fa1.uva.es)

Received: 9 January 2012 - Published in Atmos. Meas. Tech. Discuss.: 23 February 2012

Revised: 25 July 2012 - Accepted: 25 July 2012 - Published: 21 August 2012

\begin{abstract}
This paper proposes a method to obtain spectral sky radiances, at three wavelengths $(464,534$ and $626 \mathrm{~nm})$, from hemispherical sky images. Images are registered with the All-Sky Imager installed at the Andalusian Center for Environmental Research (CEAMA) in Granada (Spain). The methodology followed in this work for the absolute calibration in radiance of this instrument is based on the comparison of its output measurements with modelled sky radiances derived from the LibRadtran/UVSPEC radiative transfer code under cloud-free conditions. Previously, in order to check the goodness of the simulated radiances, these are compared with experimental values recorded by a CIMEL sunphotometer. In general, modelled radiances are in agreement with experimental data, showing mean differences lower than $20 \%$ except for the pixels located next to the Sun position that show larger errors.

The relationship between the output signal of the All-Sky Imager and the modelled sky radiances provides a calibration matrix for each image. The variability of the matrix coefficients is analyzed, showing no significant changes along a period of 5 months. Therefore, a unique calibration matrix per channel is obtained for all selected images (a total of 705 images per channel). Camera radiances are compared with CIMEL radiances, finding mean absolute differences between $2 \%$ and $15 \%$ except for pixels near to the Sun and high scattering angles. We apply these calibration matrices to three images in order to study the sky radiance distributions for three different sky conditions: cloudless, overcast
\end{abstract}

and partially cloudy. Horizon brightening under cloudless conditions has been observed together with the enhancement effect of individual clouds on sky radiance.

\section{Introduction}

Knowledge and measurements of the angular distribution of sky radiance (skylight at solar wavelengths, i.e. scattered sunlight) are important since the shape of human beings, animals, plants, etc. is not regular or oriented to the Sun. Therefore, the sky radiance distribution has an outstanding role in the evaluation of radiation reaching complex targets like the human body or studies directed towards the development of solar energy systems.

The sky radiance depends on aerosol optical properties, and thus these properties can be derived from sky radiance measurements. In this sense, different authors (e.g. Nakajima et al., 1996; Dubovik and King, 2000) proposed inversion algorithms for the retrieval of aerosol optical properties using measurements of sky radiance. Dubovik et al. (2006) and Olmo et al. (2008b) include non-spherical particles approximation in the inversion codes of Duvobik and King (2000) and Nakajima et al. (1996), respectively, to obtain the columnar aerosol size distribution, the single scattering albedo (SSA), the phase function (PF) and the asymmetry parameter from radiance measurements. To this end, Olmo et al. (2008b) used the sky radiance in the principal plane (the 
plane perpendicular to the horizon that crosses the solar zenith angle, SZA, and zenith). Therefore, measurements of sky radiance are also useful to retrieve the aerosol optical properties.

Clouds produce the strongest changes in solar radiation with a substantial decrease of the direct component and an increase of the diffuse radiation, which lead to a decrease in global radiation (Alados et al., 2000; Alados-Arboledas et al., 2003; de Miguel et al., 2011b). The influence of the cloudiness on solar radiation has a significant spectral dependence, being weaker when the wavelength is shorter (Foyo-Moreno et al., 2001; Bilbao et al., 2011; de Miguel et al., 2011a). On the other hand, the clouds can also produce the enhancement of the solar radiation at surface, reaching levels even higher than its value at the top of atmosphere (Piacentini et al., 2010; Antón et al., 2011a). Therefore, studies about the behaviour of sky radiance and clouds are important for a better understanding of cloud-radiation interaction.

Several authors have analyzed the sky radiance under different sky conditions using several types of instruments. For instance, Grant and Heisler (1997), Grant et al. (1997a) and Grant et al. (1997b) used silicon photodiodes with filters, mounted on a platform that provided for rotational and inclinational motion, to take broadband radiance measurements in the ultraviolet range under obscured overcast, translucent overcast, and clear skies. Their system took a complete measurement of sky distribution (a grid of $10^{\circ}$ zenith and $3^{\circ}$ in azimuth) in $30 \mathrm{~min}$. Vida et al. (1999) tested a cloudless radiance model using radiance measurements taken by a pyroelectric radiometer (modified to present a 5-degree effective half angle field of view), and they found the highest differences between modelled and experimental radiances close to the Sun. Weihs et al. (2000) took spectral radiance measurements under different sky conditions using a spectroradiometer connected to a tube of fore-optics ( $1^{\circ}$ field of view) mounted in a tracker programmed to cover a full sky radiance distribution (a grid of $10^{\circ}$ in zenith and azimuth) in $15 \mathrm{~min}$. Wuttke and Seckmeyer (2006) recorded measurements of sky luminance and spectral radiance using a sky scanner that took 150 points, in $40 \mathrm{~s}$, evenly distributed across the sky. Both works (Weihs et al., 2000; Wuttke and Seckmeyer, 2006) compared radiance measurements with radiative transfer models based on the discrete ordinate radiative transfer algorithm, DISORT (Stamnes et al., 2000), and the results indicated that circumsolar region shows the highest errors, and the input parameters would have to be known with greater accuracy (e.g. they do not use PF as input).

Sky cameras, or sky imagers, are devices that combine a digital camera with a fisheye lens, or a hemispherical mirror in some cases, that takes pictures of the full hemispherical sky. These instruments present two main features: firstly, they have a very high angular resolution taking measurements with a full hemispherical field of view, and secondly, these measurements are acquired simultaneously which im- plies no problems with changes in atmosphere between two consecutive measurements at different viewing angles.

Sky imagers have been used for different purposes in research. Thus, these instruments were usually utilized to obtain cloud cover using threshold values for the ratio between different wavelength channels (Long et al., 2006). Heinle et al. (2010) developed an algorithm to discern the kind of cloud, and Mannstein et al. (2010) used a sky imager to detect and study contrails and additional cirrus clouds caused by air traffic. Aerosol optical depth (AOD) and cloud cover were retrieved using the All-Sky Imager and neural networks by Cazorla et al. (2008a) and Cazorla et al. (2008b), respectively. López-Alvarez et al. (2008) derived sky radiance spectra from sky images using a linear pseudo-inverse method, and Olmo et al. (2008a) used these spectra, and an iterative method based on radiative transfer, to obtain AOD at $550 \mathrm{~nm}$. Other authors used a sky imager with filters to measure the relative sky radiance polarization (Horváth et al., 2002; Kreuter et al., 2009). Some works were performed using sky imagers carefully calibrated in the laboratory to obtain spectral radiance values (Voss and Zibordi, 1989; Zibordi and Voss, 1989; Voss and Liu, 1997; Cazorla et al., 2009).

The main aim of this paper is the calibration of a sky imager to obtain sky radiance measurements at three different wavelengths at Granada (Spain) using a radiative transfer model. The great advantage of the sky camera with respect to other instruments is its high time and spatial resolution. Additionally, the calibration method proposed in this work is simpler and cheaper than the methodologies found in literature which need laboratory calibration.

This paper is structured as follows: Sect. 2 shows the location, instrumentation and the data used in the work. Section 3 describes the methodology used to obtain cloudless sky radiance values, and these estimated values are validated using radiance measurements. The full method for obtaining sky radiance from sky images is presented in Sect. 4. Results and conclusions are in Sect. 5, where the obtained calibration matrices are tested with measurements and a qualitative analysis of three sky images is presented. Finally, the conclusions are summarized in Sect. 6.

\section{Site, instrumentation and data}

\subsection{Site}

The measurements used in this paper were taken by the Atmospheric Physics Group (GFAT, http://atmosfera.ugr.es) of the University of Granada on the rooftop of the Andalusian Center for Environmental Studies (CEAMA, $37.17^{\circ} \mathrm{N}$, $3.61^{\circ} \mathrm{W}, 680 \mathrm{~m}$ a.s.1). Experimental site and its local conditions were described in detail by Lyamani et al. (2010, 2011). 


\subsection{Instrumentation}

\subsubsection{The All-Sky Imager}

The All-Sky Imager designed and deployed by the GFAT has been operating at our experimental site since 2005 and basically consists of a digital colour CCD camera with a fisheye lens encapsulated in an environmental housing that is temperature regulated with a peltier cell. The system is installed in a Sun tracker (2AP model from Kipp \& Zonen) to block the direct solar radiation using a shadow ball. A transparent acrylic dome protects the sky imager from the weather conditions like rain or snow. This dome was changed by a glass dome (non-acrylic) in December 2010 due to degradation problems, being the new dome more stable. The camera body is a RETIGA $1300 \mathrm{C}$ (QImaging) and has a CCD sensor with three channels: red, green and blue. The CCD sensor is the model ICX085AK from Sony working with a filter that blocks the wavelengths in the infrared region (standard configuration of the camera). The spectral responses of the camera channels are shown in Fig. 1, being centred around $450 \mathrm{~nm}, 550 \mathrm{~nm}$ and $650 \mathrm{~nm}$ with a bandwidth about $100 \mathrm{~nm}$ for the blue, green, and red channel, respectively. Spectral responses show a symmetrical shape except for the red channel, because it is influenced by the infrared filter. The lens is a Fujinon FE185C057HA fisheye lens, its field of view being $185^{\circ}$, which guarantees $180^{\circ}$ field of view projected into CCD. The lens manufacturer indicates that there is no longitudinal or lateral chromatic aberration and the angular distortion is less than $0.8 \%$. The lens effect in the image was obtained using a ruler in a dome, observing that the variation of zenith angle is linear with the pixel distance (equidistant projection in the CCD), and the solid angle viewed by each pixel was calculated using this information (Cazorla, 2010). The final result of the camera is an image $(900 \times 900$ pixels) with 12-bits digitalization per channel. As an example, three recorded images can be seen in Fig. 2 for three different sky conditions: cloudless, obscured overcast and partially cloudy. There are notable differences between the three images, showing the higher response in the blue channel when the sky is cloud-free, and brighter clouds when the sky is not overcast. The Sun tracker, blocking the direct radiation, and other obstacles surrounding the camera can be appreciated in the images.

The camera was programmed to take images every $5 \mathrm{~min}$ between sunrise and sunset with an exposure time of $12 \mathrm{~ms}$. All information about the GFAT All-Sky Imager can be found in Cazorla (2010).

\subsubsection{Sunphotometer CE-318}

A sunphotometer CE-318 (CIMEL Electronic, France), which is the standard Sun/sky photometer used in the AERONET network (Holben et al., 1998), was installed next to the sky imager in the same rooftop. This instrument (in-

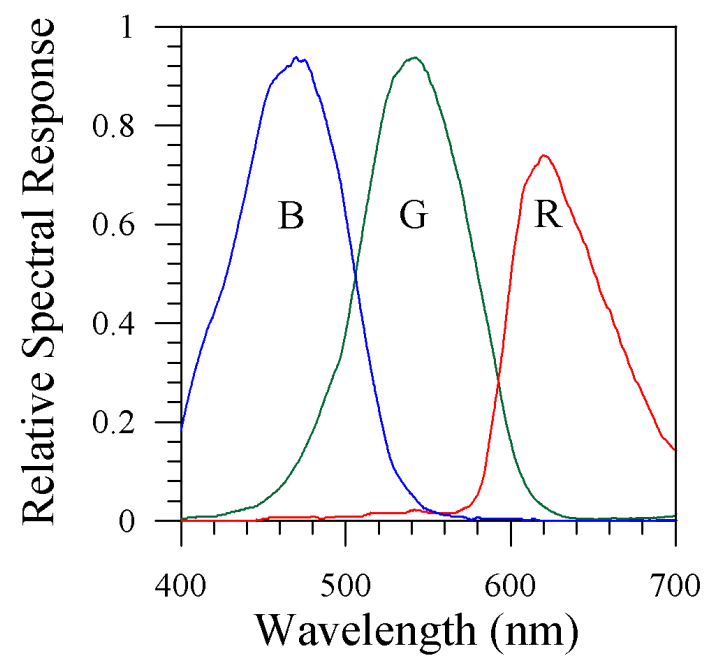

Fig. 1. Relative spectral response of the ICX085AK CCD sensor for the red $(R)$, green $(G)$ and blue (B) channels, taking into account the infrared filter included in the RETIGA $1300 \mathrm{C}$ camera.

cluded in the AERONET network) takes extinction measurements at 340, 380, 440, 500, 675, 870, 940 and $1020 \mathrm{~nm}$ using filters, and they are used to retrieve aerosol properties such as AOD and Angström coefficients at different wavelengths, except at $940 \mathrm{~nm}$ which is used to retrieve total column water vapour column.

In addition, measurements of sky radiance at 440, 500, 675,870 and $1020 \mathrm{~nm}$ are registered by the sunphotometer using a sky collimator at high gain at different angles in the principal plane and the almucantar (the circle parallel to the horizon with the zenith angle equal to the solar zenith angle, SZA) configurations. These measurements are useful to retrieval aerosol optical and microphysics properties like columnar aerosol size distribution, complex refractive index, PF and SSA at different wavelengths following the AERONET procedures (Holben et al., 1998; Dubovik and King, 2000).

Calibration of this instrument was performed annually by AERONET-RIMA network. More details about CIMEL CE318-4 can be found in Holben et al. (1998).

\subsection{Data set}

Different measurements were used in this work. From the measurements recorded by the All-Sky Imager, we only work with those recorded during the year 2011 in order to guarantee images with the glass dome.

On the other hand, the aerosol information was obtained from the CIMEL sunphotometer. Thus, the Angström $\alpha$ parameter was calculated using AOD at 440 and $675 \mathrm{~nm}$, and the Angström $\beta$ parameter was obtained taking into account $\alpha$ and $\mathrm{AOD}$ at $500 \mathrm{~nm}$ : 


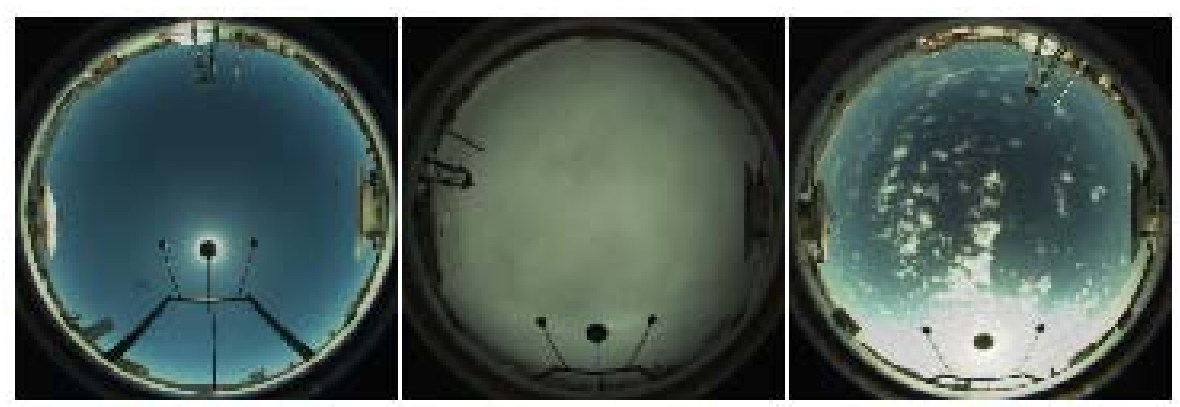

Fig. 2. Sky images taken by the All-Sky Imager of GFAT for three different conditions: a cloudless sky (8 July 2011, 13:15 UTC) on the left, an obscured overcast sky (23 January 2011, 10:35 UTC) in the middle, and a partially cloudy sky (7 March 2011, 16:15 UTC) on the right.

$\alpha=\frac{\log \left(\frac{\mathrm{AOD}_{440}}{\mathrm{AOD}_{675}}\right)}{\log \left(\frac{675}{440}\right)}$,

$\beta=\frac{\mathrm{AOD}_{500}}{0.5^{-\alpha}}$

In addition, the sunphotometer sky radiances measured with the $440 \mathrm{~nm}$ and $675 \mathrm{~nm}$ filters were provided by AERONET, but the products of the network are the radiances at the nominal wavelengths of $441 \mathrm{~nm}$ and $677 \mathrm{~nm}$ due to the filter bandwidth. Radiance measurements using the $500 \mathrm{~nm}$ filter (nominal wavelength of $501 \mathrm{~nm}$ ) are only available along two months in 2011, but they were used to test the calibration method in Sect. 5.1. Additionally, SSA values were also used in the work and, how they are retrieved using sky radiances, AERONET provides these values at the nominal wavelengths of 441 and $677 \mathrm{~nm}$. The SSA values are only available at 441 and $677 \mathrm{~nm}$, but we used the SSA at $550 \mathrm{~nm}$, which was estimated as the mean between $\mathrm{SSA}_{441}$ and $\mathrm{SSA}_{677}$. Similar method was followed for the PF values, which are only available at 441 and $677 \mathrm{~nm}$ (nominal wavelengths) in AERONET, and thus $\mathrm{PF}_{550}$ was estimated as the mean between $\mathrm{PF}_{441}$ and $\mathrm{PF}_{677}$ for each scattering angle. Finally, water vapour column values, provided by AERONET, were estimated using Sun direct measurements. All mentioned data provided by AERONET can be downloaded visiting the website http://aeronet.gsfc.nasa.gov.

The daily total ozone column, TOC, used in this work was measured by several satellite-based remote sensing instruments: OMI collected in the Aura satellite (downloaded from http://disc.sci.gsfc.nasa.gov/giovanni) and GOME and GOME-2 data (supplied by the staff of the Remote Sensing Technology Institute, IMF, of the German Aerospace Centre, DLR). These satellite data show, in general, an excellent agreement with reference ground-based measurements (Antón et al., 2009a, b).

\section{Modelling cloudless sky radiance}

The methodology used in this work for the absolute calibration in radiance of the All-Sky Imager is based on the comparison of its output measurements with the sky radiance values estimated by the UVSPEC radiative transfer model under cloud-free conditions. This section presents the description of the inputs used in the code and the validation of the modelled radiance values against experimental data measured by the CIMEL sunphotometer.

\subsection{UVSPEC model}

The reference values of sky radiance were estimated by the LibRadtran software package (the 1.6 beta version was used in this paper), which main tool is the UVSPEC model, developed by Mayer and Kylling (2005). The various radiative transfer equation solvers included in the UVSPEC have different capabilities to calculate the radiative quantities in the Earth's atmosphere. The radiative solver chosen to obtain sky radiance, on the Earth's surface, was an improved version of the DISORT algorithm in $\mathrm{C}$ language (CDISORT) running in 18 stream mode. This solver was developed by Buras et al. (2011), and it uses the correction developed by Nakajima and Tanaka (1988) applying the directional distribution after secondary scattering of light in an atmosphere.

We run the UVSPEC model using the standard profiles and inputs indicated by Antón et al. (2011b) for the GFAT station at Granada. The standard atmosphere was mid-latitudes summer (from May to October) and winter (the rest of months). The extraterrestrial spectrum used was the proposed by Gueymard (2005). Surface albedo was considered as a fixed value of 0.2 for all wavelengths. Daily TOC was included in the inputs, and all simulations were run under cloud-free conditions.

For aerosols, the appropriated spring-summer and fallwinter profiles given by Shettle (1989) were used. We chose an urban aerosol profile in the lower $2 \mathrm{~km}$ of the atmosphere and a background profile above $2 \mathrm{~km}$, and the impact of the aerosol loading in the boundary was expressed by columnar $\alpha$ and $\beta$ Angström coefficients (see Sect. 2.3) which 
are scaled in the chosen profiles. Legendre moments were used as phase function information input, and these moments were calculated using the PMOM tool, included in LibRadtran package, which calculates the Legendre moments of a given phase function. The PMOM tool was run to obtain 200 moments with a scattering angle grid resolution for moderate forward peaks. The SSA and PF as inputs depended on the wavelength of the estimated radiance.

Finally, the UVSPEC outputs for each simulation were the radiances, in $\mathrm{m} \mathrm{W} \mathrm{m}^{-2} \mathrm{~nm}^{-1} \mathrm{sr}^{-1}$, at a selected wavelength each $5^{\circ}$ and $1^{\circ}$ in azimuth and zenith angles, respectively.

\subsection{Modelled vs. experimental radiance}

Sky radiances measured by the CIMEL sunphotometer were used to study the reliability of the UVSPEC modelled radiances. For this goal, 50 almucantar cloudless measurements of radiance at 441 and $677 \mathrm{~nm}$ were chosen randomly. The cloudless radiances were calculated using UVSPEC and the inputs explained above, but changing the output angles for the almucantar angles and selecting the wavelengths of the sunphotometer. In addition, $\mathrm{SSA}_{441}$ and $\mathrm{PF}_{441}$ were used as input for the calculations of radiance at $441 \mathrm{~nm}$ and $\mathrm{SSA}_{677}$ and $\mathrm{PF}_{677}$ for the radiance at $677 \mathrm{~nm}$.

The absolute value of the relative error, ARE, between modelled and experimental values was calculated, for each scattering angle, by the next equation:

$\chi(\%)=100 \% \frac{\left|R_{\mathrm{MOD}}-R_{\mathrm{MEAS}}\right|}{R_{\mathrm{MEAS}}}$,

where $\chi$ is the $\mathrm{ARE}$, and $R_{\mathrm{MOD}}$ and $R_{\mathrm{MEAS}}$ are the modelled (UVSPEC) and measured (CIMEL) sky radiances, respectively. ARE values were calculated for each scattering angle, which depends on the azimuth angle relative to the Sun's azimuth and the SZA (Nakajima et al., 2006). Intervals of the scattering angle with a width of $5^{\circ}$ were taken using the 50 random values (random solar zenith angles), and Fig. 3 shows the mean (panel a) and the median (panel b) of these intervals for the two wavelengths. The figure includes the standard deviation (error bars), which is only half represented (up or down) for $677 \mathrm{~nm}$ due to the high value. The mean value of ARE for the sky radiance at $677 \mathrm{~nm}$ is about $60 \%$ when the scattering angle is around $0^{\circ}$. In contrast, the behaviour is remarkably good for angles far from the Sun. Thus, the mean parameter varies between $4 \%$ and $10 \%$ for scattering angles larger than $10^{\circ}$ and the standard deviation is quite lower than near the Sun. Figure $3 \mathrm{~b}$ shows that the median values of ARE at $677 \mathrm{~nm}$ are smaller than $10 \%$ for all scattering angles. This high difference between the median and mean of ARE at $677 \mathrm{~nm}$ for cases close to the Sun indicates that only a few modelled cases significantly differ with respect to the experimental data when the scattering angle is around $0^{\circ}$. On the other hand, the mean and median values of ARE at $441 \mathrm{~nm}$ range are smaller for low scattering angles, and these values are lower than $20 \%$ for all scattering

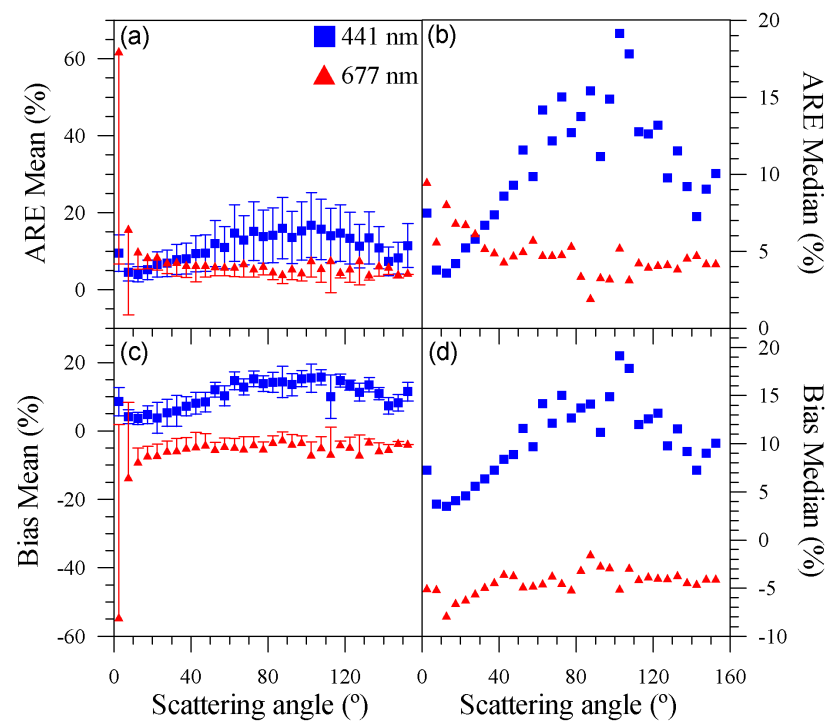

Fig. 3. Mean (left panels) and median (right panels) of the absolute relative error (ARE; upper panels) and bias (down panels) between sky radiance calculated by UVSPEC and measured by CIMEL for 441 and $677 \mathrm{~nm}$ as a function of the scattering angle in the almucantar. The error bars represent the standard deviation, of which only half (up or down) is included for $677 \mathrm{~nm}$ due to the high values near to the Sun.

angles. In addition, the mean and median of the bias (relative difference taking into account the sign) are shown in panels c and $d$. These values suggest systematic differences between the modelled values and the measurements with an underestimation of the model for $677 \mathrm{~nm}$ and an overestimation for $441 \mathrm{~nm}$.

Therefore, the sky radiance estimated with the UVSPEC model, and used in this work as reference for the calibration of the All-Sky Imager, presents differences with respect to the experimental ones smaller than $20 \%$ and $10 \%$ for $441 \mathrm{~nm}$ and $677 \mathrm{~nm}$, respectively. Nevertheless, we have decided to avoid the use of the UVSPEC simulations for those cases near to the Sun (azimuth angle relative to Sun smaller than $10^{\circ}$ ).

\section{Calibration method}

This section describes the method followed to obtain the calibration matrix of the All-Sky Imager and, thus, to convert the output signal of each pixel and channel in the sky radiance that reaches every pixel under cloud-free conditions. Both modelled and experimental sky radiances could be used as reference in the calibration method. In this work, we have employed modelled values derived from a radiative transfer model instead of experimental measurements due to two reasons: the effective wavelength and the field of view. Thus, while the effective wavelengths of the camera channels differ from the sunphotometer ones, the use of a radiative transfer 
code allows to simulate sky radiances at the same effective wavelengths of the camera channels. In addition, the use of experimental sky radiances is only useful for one pixel calibration but using a radiative transfer model all pixels can be calibrated.

\subsection{Effective wavelength}

In order to obtain the radiance reaching the All-Sky Imager at every pixel, it is necessary to simulate spectral radiance between 400 and $700 \mathrm{~nm}$ and weight them using the spectral response shown in Fig. 1 for each channel. This process expends a lot of computation time; moreover, we are interested in obtaining spectral radiance instead of broadband. This issue is solved using the concept of effective wavelength (Kholopov, 1975). The ratio of two broadband measurements, taken with the same instrument, with its self spectral response, under different conditions, is also equal to the ratio of the same measurements but measured with an instrument that only is sensitive at the effective wavelength, $\lambda_{\mathrm{e}}$. Therefore, the effective wavelength for each channel is calculated using the following expression:

$$
\lambda_{\mathrm{e}}=\frac{\int_{\lambda} \lambda I(\lambda) S(\lambda) d \lambda}{\int_{\lambda} I(\lambda) S(\lambda) d \lambda},
$$

where $\lambda$ is the wavelength, $I$ is the irradiance reaching the instrument, and $S$ is the spectral response of the channel (Fig. 1). In order to calculate $\lambda_{\mathrm{e}}$, a different set of irradiances reaching the camera is simulated using the UVSPEC model. A total of 200 simulations of spectral diffuse irradiance (direct irradiance does not reach the camera) were simulated per channel. The phase function used in these simulations is the Henyey-Greenstein function. In addition, the values of the asymmetry parameter and SSA are 0.7 and 0.9 , respectively, and a fixed TOC value of 300 DU is utilized for all wavelengths under a mid-latitudes summer atmosphere.

The 200 simulations for each channel (600 in total) were run changing SZA (from $10^{\circ}$ to $80^{\circ}$ in $10^{\circ}$ steps), $\alpha$ parameter (from 0.2 to 1.8 in 0.4 steps) and $\beta$ parameter (from 0.01 to 0.21 in 0.05 steps). Thus, 200 effective wavelengths per channel were calculated by Eq. (4) using the simulated spectral diffuse irradiances. The mean values were $464 \mathrm{~nm}$ (blue), $534 \mathrm{~nm}$ (green) and $626 \mathrm{~nm}$ (red), with a standard deviation of $2 \mathrm{~nm}$ for the three channels. Therefore, the spectral radiance reaching the camera is simulated at these three effective wavelengths as is described in Sect. 3.1, taking into account that the SSA and PF values used as inputs are $\mathrm{SSA}_{441}$ and $\mathrm{PF}_{441}$ to estimate the radiance at $464 \mathrm{~nm}, \mathrm{SSA}_{550}$ and $\mathrm{PF}_{550}$ for $534 \mathrm{~nm}$, and $\mathrm{SSA}_{677}$ and $\mathrm{PF}_{677}$ for $626 \mathrm{~nm}$.

\subsection{Calibration matrix}

First, a cloudless image is selected, being separated in the red, green and blue images. We mask the zenith angles higher than $80^{\circ}$, the pixels near to the Sun, and the different obstacles around the whole sky like the shadow system and the two pyranometers installed on the tracking system near the camera (see Fig. 2). In the next step, the pixel counts were normalized to unity using the ratio between the raw value and the highest recorded value $\left(2^{16}\right)$. Finally, the dark noise signal was removed taking into account that, in all rows and columns of an image, a dark zone appears whose signal must be null (as a first approximation). Therefore, the minimum values for each column and each row were averaged and considered as the dark signal, which was subtracted to the normalized signal. Some authors (e.g. Voss and Zibordi, 1989; Voss and Liu, 1997) found problems related to the lens since its transmittance varies with the field of view. However, in this work, this issue was not considered because the calibrated system consists of the CCD with the lens together, and the field of view of the lens presents no significant changes in the pixels between different images due to the angular symmetry.

The corrected image is a $900 \times 900$ matrix, $\mathbf{P}$, which $P_{i j}$ element is the corrected raw signal for the $i j$-pixel. This signal should be proportional to the incident radiation: radiance that reaches the $i j$-pixel multiplied by the solid angle of that view, $\Omega_{i j}$. Therefore, a $900 \times 900$ matrix, $\mathbf{R}$, was constructed using the simulated radiance values (Sects. 3.1 and 4.1) and interpolating for each pixel. Therefore, the matrix calibration, $\mathbf{K}$, can be expressed as

$\mathbf{K}=\frac{\mathbf{R} \Omega}{\mathbf{P}}$.

This relationship is only valid if the response of the CCD sensor is lineal. The raw signal of the CCD, without removing the dark noise, was represented as a function of the simulated sky radiance for different cloudless images (not shown). The results indicate that the CCD response is linear for normalized raw values smaller than 0.8 , being the pixel saturated for a signal higher than 0.8 . Therefore, the pixels with normalized signal higher than 0.8 (before the subtraction of the dark noise) were removed along with their eight neighbours due to blooming effect (Voss and Liu, 1997).

From the method described here, given a cloudless image, three calibration matrices (K-RED, K-GREEN and KBLUE) are calculated using Eq. (5). These matrices can be used to calculate the radiance at 464,534 and $626 \mathrm{~nm}$ multiplying the specific $\mathbf{K}$ matrix by the specific channel of the image and dividing this value by the solid angle viewed for each pixel.

\subsection{Matrix calibration variability}

A set of cloudless images were selected to study the variability of the matrix elements $\left(K_{i j}\right)$. The dates of the eight chosen days along with the initial and final time of their image set (every $5 \mathrm{~min}$ ) are presented in Table 1 . These days were selected to study the variability between consecutive days 
(day 1 to 4 ), and the variability in a long period (5 months) from winter days (day 1 to 6) to summer ones (day 7 and 8 ). Moreover, the eight selected days were completely cloudfree in order to see the intra-daily variation of the calibration matrix. Therefore, a $\mathbf{K}$ matrix can be obtained for each image recorded during the eight days shown in Table 1.

In order to analyze the influence of SZA on the $K_{i j}$ elements, we evaluated the variability for each $i j$-pixel over a whole day. Thus, the intra-daily coefficient of variation, $\boldsymbol{\Gamma}$, was calculated for each $i j$-pixel:

$\boldsymbol{\Gamma}_{i j}=100 \% \frac{\sigma\left(K_{i j, T}\right)}{M\left(K_{i j, T}\right)}$,

where $\sigma\left(K_{i j, T}\right)$ and $M\left(K_{i j, T}\right)$ are the standard deviation and the mean of the several values of $K_{i j}$ throughout the day. Thus, $\boldsymbol{\Gamma}$ is a matrix whose elements indicate the daily variation of each $K_{i j}$.

Table 2 shows the percentage of $K_{i j}$ elements with $\Gamma$ lower than $10 \%$ and the mean value of $\boldsymbol{\Gamma}$ for each day. It can be seen that the intra-daily variation of the coefficients of the matrix calibration is small, with a mean value between $3.1 \%$ and $5.4 \%$ for all days and channels. In addition, the percentage of coefficients with variations lower than $10 \%$ is near to $100 \%$ for all days. These results justify that we assume that $\mathbf{K}$-RED, K-GREEN and K-BLUE do not depend on SZA, and that daily mean $\mathbf{K}$ matrix, $\mathbf{K}_{\mathrm{d}}$, obtained as the average of all calculated $\mathbf{K}$ matrices in a day can be considered representative for that day. Thus, $\mathbf{K}_{\mathrm{d}}$ is calculated for the eight selected days, and the resulting matrices are compared to each other The matrix with the absolute difference between the $\mathbf{K}_{\mathrm{d}}$ of the m-day $\left(\mathbf{K}_{\mathrm{d}, \mathrm{m}}\right)$ and the n-day $\left(\mathbf{K}_{\mathrm{d}, \mathrm{n}}\right)$ is obtained as

$\Delta \mathbf{K}_{\mathrm{d}, \mathrm{m}, \mathrm{n}}(\%)=100 \% \frac{\left|\mathbf{K}_{\mathrm{d}, \mathrm{m}}-\mathbf{K}_{\mathrm{d}, \mathrm{n}}\right|}{\mathbf{K}_{\mathrm{d}, \mathrm{n}}}$.

Table 3 reports about the inter-comparison between the eight days, showing the percentage of pixels with a difference lower than $10 \%\left(\Delta \mathbf{K}_{\mathrm{d}, \mathrm{m}, \mathrm{n}}<10 \%\right)$ and the mean of these differences in parentheses. The mean difference between the days 1, 2 and 3 is smaller than $2 \%$ with $99.9 \%$ of pixels with a difference lower than $10 \%$. This result indicates low variation in $\mathbf{K}$ between consecutive days. The highest mean difference between two winter days is $2.9 \%, 4.0 \%$ and $4.5 \%$ for the red, green and blue channels, respectively. Moreover, the percentage of pixel with a difference lower than $10 \%$ is always higher than $99 \%$ when the winter days are compared for all channels. Table 3 also shows that the differences increase when day 7 is compared with the other days, being stronger in the green channel. This fact could be explained by some problematic images in day 7 , because this day also shows the worst behaviour in Table 2. Nevertheless, the differences between day 7 and the others are smaller than $6.1 \%$, being within the margin of error given by the cloudless modelling. The highest value of $\Delta \mathbf{K}_{\mathrm{d}, \mathrm{m}, \mathrm{n}}$ (not shown in Table 3) ranges from $14.8 \%$ to $57.6 \%$, from $19.3 \%$ to $152.5 \%$, and
Table 1. Image set, showing day, month, and time interval (images are every $5 \mathrm{~min}$ ).

\begin{tabular}{lcccc}
\hline $\begin{array}{l}\text { Day of } \\
\text { month }\end{array}$ & Month & Day & $\begin{array}{c}\text { Initial } \\
\text { Time (UTC) }\end{array}$ & $\begin{array}{c}\text { Final } \\
\text { Time (UTC) }\end{array}$ \\
\hline 13 & 1 & 1 & $08: 35$ & $16: 10$ \\
14 & 1 & 2 & $08: 35$ & $16: 15$ \\
15 & 1 & 3 & $08: 35$ & $16: 15$ \\
16 & 1 & 4 & $08: 30$ & $16: 15$ \\
2 & 2 & 5 & $08: 20$ & $16: 35$ \\
4 & 2 & 6 & $08: 15$ & $16: 40$ \\
16 & 6 & 7 & $06: 15$ & $16: 30$ \\
19 & 6 & 8 & $05: 55$ & $10: 30$ \\
\hline
\end{tabular}

Table 2. Percentage of elements of $\boldsymbol{\Gamma}$ lower than $10 \%$, for each day and channel. The mean value of $\boldsymbol{\Gamma}$ is given in parentheses.

\begin{tabular}{lrrr}
\hline Day & Red & Green & Blue \\
\hline 1 & $97.1(5.4)$ & $99.1(4.4)$ & $100(3.9)$ \\
2 & $99.1(5.3)$ & $99.4(4.3)$ & $99.3(4.1)$ \\
3 & $99.9(4.5)$ & $100(3.5)$ & $100(3.1)$ \\
4 & $99.8(4.9)$ & $99.9(3.9)$ & $99.9(3.5)$ \\
5 & $100(4.8)$ & $100(4.1)$ & $100(4.5)$ \\
6 & $99.0(5.3)$ & $100(4.2)$ & $99.9(3.9)$ \\
7 & $98.0(5.3)$ & $99.2(4.9)$ & $96.0(5.2)$ \\
8 & $99.6(4.0)$ & $100(3.4)$ & $100(3.5)$ \\
\hline
\end{tabular}

from $16.8 \%$ to $146.8 \%$ for red, green and blue channels, respectively.

Once we have observed that the variability of $K_{i j}$ elements is not significant, a unique calibration matrix for each channel can be derived from all images recorded during the eight selected days (a total of 705 images per channel). Figure 4 shows three images with the calibration matrices and their standard deviation, both in $\mathrm{m} \mathrm{W} \mathrm{m}^{-2} \mathrm{~nm}^{-1} \mathrm{raw}^{-1}$. The matrices' coefficients show uniformity for all angles in the three channels. The coefficient of variation is below $10 \%$ in $99 \%$ of the pixels, and its mean is lower than $6 \%$ for all channels. However, a few pixels (less than $1 \%$ ) show large variability (white pixels for the standard deviation images in Fig. 4). This high deviation could be related to occasional little spots.

Therefore, the three calibration matrices shown in Fig. 4 can be applied to the raw data measured by the All-Sky Imager and, thus, the sky radiance can be estimated at 464, 534 and $626 \mathrm{~nm}$ for all sky conditions.

\section{Results and discussion}

\subsection{Validation of the calibration method}

The reliability of the calibration method is analyzed in this section by means of the comparison between the spectral radiances derived from the camera and experimental values 
Table 3. Contingency table showing the percentage of elements of $\Delta \mathbf{K}_{\mathrm{d}, \mathrm{m}, \mathrm{n}}$ smaller than $10 \%$ as a function of days and channels. The mean $\Delta \mathbf{K}_{\mathrm{d}, \mathrm{m}, \mathrm{n}}$ is given in the parentheses.

\begin{tabular}{|c|c|c|c|c|c|c|c|c|c|}
\hline Channel & Day & 1 & 2 & 3 & 4 & 5 & 6 & 7 & 8 \\
\hline \multirow{8}{*}{ Red } & 1 & - & $100(1.3)$ & $100(1.3)$ & $99.9(2.9)$ & 99.7 (2.0) & $99.6(1.9)$ & $78.5(6.1)$ & $99.0(2.9)$ \\
\hline & 2 & $100(1.3)$ & - & $100(1.0)$ & $99.8(2.0)$ & $99.4(1.8)$ & $99.6(1.3)$ & $88.9(5.3)$ & $98.5(2.6)$ \\
\hline & 3 & $100(1.3)$ & $100(1.0)$ & - & $99.8(2.0)$ & $99.1(2.3)$ & $99.6(1.6)$ & $86.2(5.5)$ & $98.9(2.7)$ \\
\hline & 4 & $99.9(2.8)$ & $100(2.0)$ & 99.9 (1.9) & - & $99.5(3.0)$ & $99.6(2.0)$ & $93.6(4.9)$ & $97.5(3.5)$ \\
\hline & 5 & $99.6(2.0)$ & $99.4(1.8)$ & $99.5(2.3)$ & $99.4(3.1)$ & - & $99.3(1.7)$ & $87.0(5.5)$ & $98.6(2.7)$ \\
\hline & 6 & $99.6(1.9)$ & $99.6(1.3)$ & $99.6(1.5)$ & $99.6(2.1)$ & 99.4 (1.6) & - & $91.6(5.0)$ & $98.0(2.5)$ \\
\hline & 7 & $83.2(5.8)$ & $93.5(5.1)$ & $91.3(5.3)$ & $95.5(4.9)$ & $92.0(5.3)$ & $95.7(4.8)$ & - & $98.0(3.8)$ \\
\hline & 8 & 98.7 (2.9) & $98.1(2.7)$ & $98.7(2.7)$ & $97.1(3.7)$ & $97.9(2.7)$ & $97.6(2.6)$ & $96.6(4.0)$ & - \\
\hline \multirow{8}{*}{ Green } & 1 & - & $100(1.4)$ & $100(1.9)$ & $99.9(4.0)$ & $99.9(1.5)$ & 99.9 (1.7) & $69.1(7.0)$ & $99.5(4.1)$ \\
\hline & 2 & $100(1.4)$ & - & $99.9(0.8)$ & $99.9(2.6)$ & 99.9 (1.9) & $99.8(1.0)$ & $77.8(6.1)$ & 99.9 (3.2) \\
\hline & 3 & $99.9(1.8)$ & $99.9(0.8)$ & - & $99.8(2.2)$ & $99.9(2.3)$ & $99.8(1.2)$ & $79.4(5.9)$ & $99.7(3.1)$ \\
\hline & 4 & $100(3.8)$ & $99.9(2.5)$ & $99.8(2.2)$ & - & $99.8(4.0)$ & $99.7(2.8)$ & $91.6(5.0)$ & $99.8(2.6)$ \\
\hline & 5 & $99.9(1.5)$ & $99.8(1.9)$ & $99.9(2.4)$ & 99.7 (4.2) & - & 100 (1.6) & 70.7 (6.6) & 99.9 (3.9) \\
\hline & 6 & 99.8 (1.6) & $99.8(1.0)$ & $99.8(1.2)$ & $99.6(2.9)$ & $100(1.6)$ & - & $78.7(5.8)$ & $99.8(2.9)$ \\
\hline & 7 & $73.8(6.4)$ & $83.2(5.7)$ & $85.9(5.6)$ & $95.7(4.9)$ & $77.5(6.0)$ & $86.1(5.4)$ & - & $99.5(3.0)$ \\
\hline & 8 & $99.9(3.9)$ & $99.9(3.1)$ & $99.8(3.0)$ & $99.8(2.7)$ & $100(3.7)$ & $99.8(2.8)$ & $98.9(3.2)$ & - \\
\hline \multirow{8}{*}{ Blue } & 1 & - & $100(1.3)$ & $100(2.0)$ & $99.9(4.5)$ & $99.8(1.4)$ & $99.8(1.6)$ & $73.6(6.5)$ & $94.0(4.8)$ \\
\hline & 2 & $100(1.3)$ & - & $100(0.8)$ & $99.9(3.3)$ & $99.8(1.8)$ & 99.7 (1.1) & $80.9(5.8)$ & $99.6(3.8)$ \\
\hline & 3 & $100(2.0)$ & $100(0.8)$ & - & $99.8(2.7)$ & $99.8(2.0)$ & 99.7 (1.3) & $85.4(5.4)$ & $99.6(3.4)$ \\
\hline & 4 & $99.9(4.3)$ & $99.9(3.2)$ & $99.9(2.6)$ & - & $99.4(4.3)$ & $99.7(3.4)$ & $94.5(4.9)$ & $99.7(2.8)$ \\
\hline & 5 & $99.8(1.4)$ & $99.7(1.8)$ & $99.7(2.1)$ & $98.6(4.5)$ & - & $100(1.5)$ & $78.8(5.8)$ & $97.7(4.5)$ \\
\hline & 6 & 99.8 (1.6) & $99.7(1.1)$ & 99.7 (1.3) & $99.4(3.5)$ & $100(1.5)$ & - & $84.8(5.3)$ & 99.8 (3.6) \\
\hline & 7 & $78.0(6.0)$ & $87.2(5.4)$ & $90.9(5.1)$ & $95.6(4.9)$ & $85.0(5.4)$ & $90.2(5.0)$ & - & 99.9 (2.6) \\
\hline & 8 & $98.4(4.5)$ & $99.8(3.6)$ & $99.8(3.3)$ & $99.6(2.8)$ & $99.6(4.3)$ & $99.8(3.4)$ & $99.8(2.6)$ & - \\
\hline
\end{tabular}

measured by the CIMEL sunphotometer. While this instrument measures the radiance at 441,501 and $677 \mathrm{~nm}$, the effective wavelengths of the camera are 464, 534 and $626 \mathrm{~nm}$. To solve these differences in the wavelengths of the channels, we obtain the ratios between the radiances at $677 \mathrm{~nm}$ and $626 \mathrm{~nm}$ (RatioR), $501 \mathrm{~nm}$ and $534 \mathrm{~nm}$ (RatioG), and $441 \mathrm{~nm}$ and $464 \mathrm{~nm}$ (RatioB) using the same 200 spectra of diffuse irradiance calculated in Sect. 4.1 . The averages ( \pm standard deviation) of these ratios are $0.87 \pm 0.07$ (RatioR), $1.13 \pm 0.06$ (RatioG) and $0.98 \pm 0.05$ (RatioB). The camera radiance in a given solar direction was obtained as the average of the closest pixels in that direction (a square of 25 pixels). Thus, the multiplication of these radiances for the three averages ratios results in the estimation of the camera radiance at the CIMEL wavelengths.

Figure 5 shows the cloudless sky radiance measured by the sunphotometer and the estimations given by camera for the almucantar (left) and principal plane (right). Each panel corresponds to a particular case which was randomly selected with the unique condition that the time difference between the CIMEL and the camera measurements must be smaller than $10 \mathrm{~min}$. It can be seen that CIMEL and camera radiances show a similar behaviour and sensitivity to scattering angle.

To evaluate the camera-CIMEL differences, the ARE mean values are calculated using 40 random cloudless im- ages for $677 \mathrm{~nm}$ and $441 \mathrm{~nm}$ and 11 images for $501 \mathrm{~nm}$. Figure 6 shows the variability of this parameter and its standard deviation (error bars) for the almucantar (panel a) and principal plane (panel b). For the almucantar configuration, the ARE mean was calculated for $5^{\circ}$ intervals of scattering angles. However, for the principal plane, the ARE averages were done for each zenith angle measured by CIMEL because zenith and scattering angle are the same in that geometry. It can be observed that the errors in almucantar configuration are lower than $15 \%$ for all scattering angles except near to the Sun (and far to the Sun at $501 \mathrm{~nm}$ ) when the disagreement experiences a notable increase. For the three wavelengths, the errors in the principal plane are also smaller than $15 \%$ except for the lowest and highest scattering angles. The bias (panels $\mathrm{c}$ and d) indicates that these differences are systematic, and that the camera overestimates the measurements at $441 \mathrm{~nm}$ (almucantar and principal plane) and at $677 \mathrm{~nm}$ (principal plane) except for angles near to the Sun, and it underestimates the radiance measurements at $501 \mathrm{~nm}$ (almucantar and principal plane) and at $677 \mathrm{~nm}$ (almucantar). These errors are similar to those obtained between the UVSPEC simulations and CIMEL (Fig. 3). Therefore, the proposed method and the obtained $\mathbf{K}$ matrices can be considered valid to estimate sky radiances. 

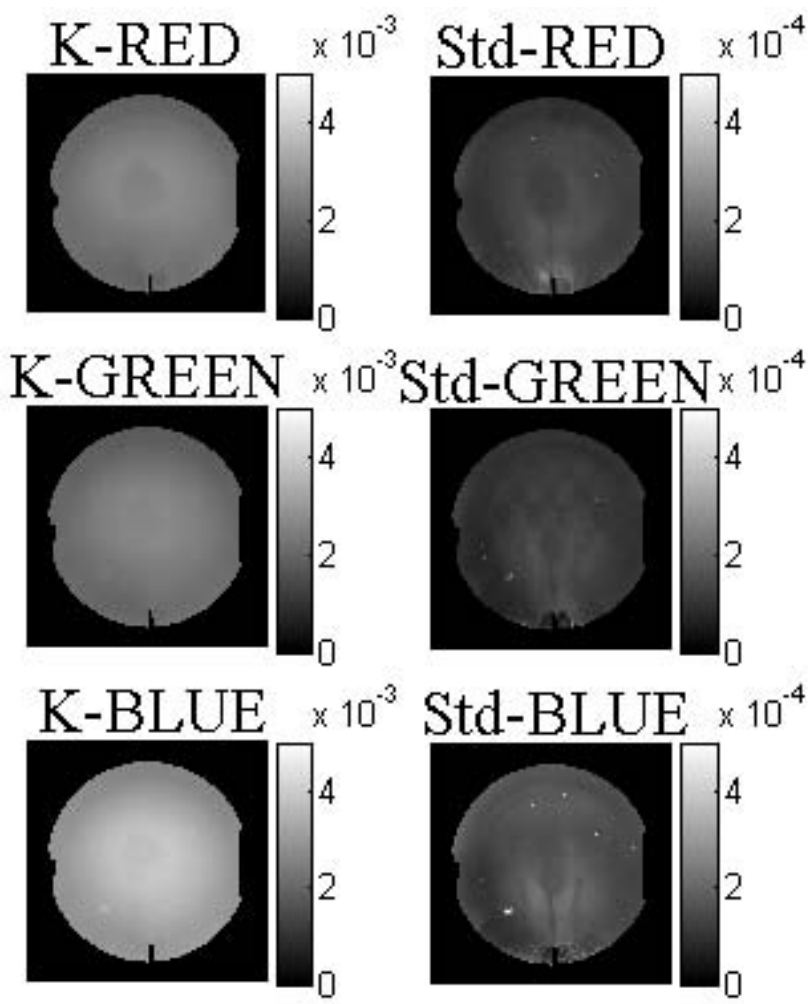

Fig. 4. Calibration matrices and their standard deviation (Std) in $\mathrm{m} \mathrm{W} \mathrm{m}^{-2} \mathrm{~nm}^{-1} \mathrm{raw}^{-1}$, for the three channels.

The obtained errors in the camera radiances are higher than the sky radiances measured by CIMEL and used in inversion algorithms for aerosol properties. Therefore, the proposed method to obtain spectral radiance from a sky camera cannot be considered useful to estimate aerosol properties with inversion codes, but it can be useful for other applications related to cloud properties or aerosol optical properties such as AOD, $\alpha$ and $\beta$.

\subsection{Application of the calibration matrices}

Spectral sky radiances were calculated for three cases shown in Fig. 2, which correspond to three different sky conditions.

Figure 7 (up) shows the sky radiance at 626, 534 and $464 \mathrm{~nm}$ (from left to right) under cloud-free conditions. It can be seen that the sky radiance decreases with wavelength increasing due to the strong spectral dependence of the molecular scattering. In addition, high radiance values are observed in the aureole along with a horizon brightening in the three wavelengths, in accordance with Wuttke and Seckmeyer (2006) who concluded that the reason for the horizon brightening can be explained by scattering processes in the atmosphere. The means ( \pm standard deviation) of all pixel values are $29( \pm 10), 53( \pm 17)$ and $88( \pm 24) \mathrm{m} \mathrm{W} \mathrm{m}^{-2} \mathrm{~nm}^{-1} \mathrm{sr}^{-1}$ for the 626,534 and $464 \mathrm{~nm}$ wavelengths, respectively. The variation coefficient increases with the wavelength.

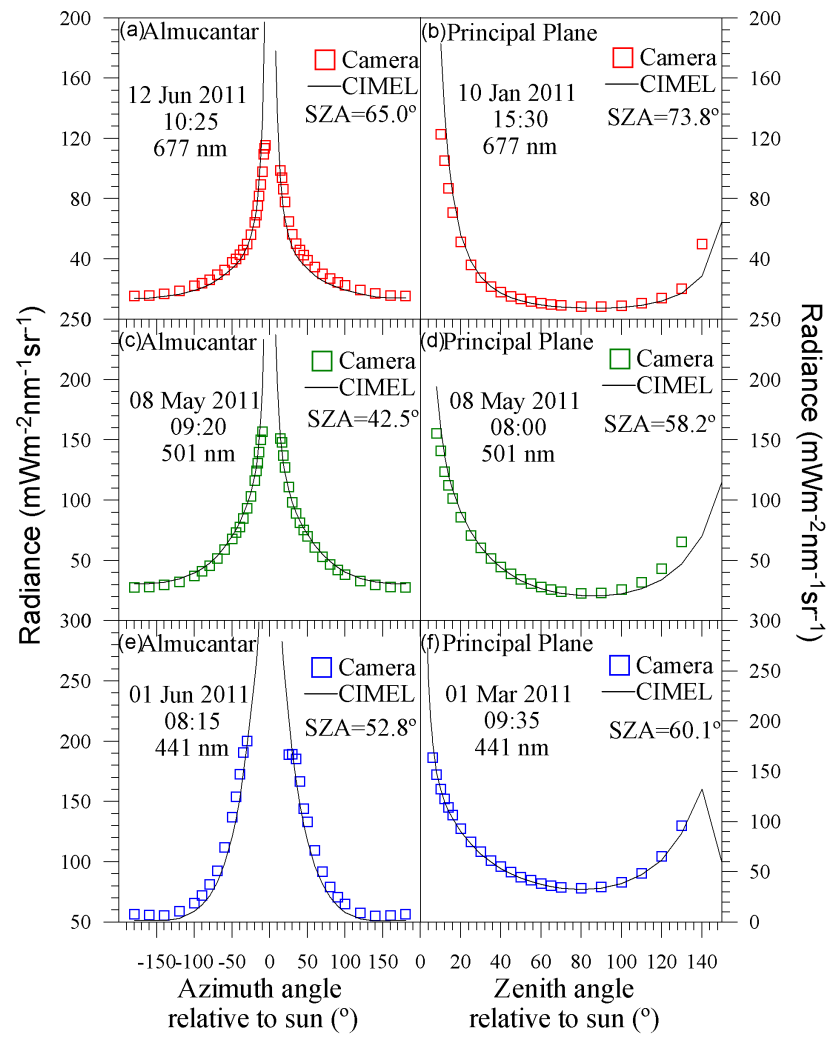

Fig. 5. The CIMEL and camera sky radiances together for two different dates at $677 \mathrm{~nm}(\mathbf{a}, \mathbf{b}), 501 \mathrm{~nm}(\mathbf{c}, \mathbf{d})$ and $441 \mathrm{~nm}(\mathbf{e}, \mathbf{f})$. Left panels represent almucantar, and right panels are principal planes.

The radiance under obscured overcast conditions shows an opposite behaviour compared to under cloudless conditions. Thus, Fig. 7 (middle) shows that the radiances decrease when the zenith angle increases, which was related by Grant and Heisler (1997) in the visible and ultraviolet range. The highest radiances appear at $464 \mathrm{~nm}$, and the radiance distribution looks more homogenous at $626 \mathrm{~nm}$. In this case, the means ( \pm standard deviation) are $71( \pm 14), 80$ $( \pm 16)$ and $92( \pm 18) \mathrm{m} \mathrm{W} \mathrm{m}^{-2} \mathrm{~nm}^{-1} \mathrm{sr}^{-1}$ for the 626,534 and $464 \mathrm{~nm}$ wavelengths, respectively. The standard deviation is lower than in the cloudless sky, which is in accordance with the higher homogeneity of radiance distribution under overcast. For these images, the variation coefficients are similar for the three wavelengths, around $20 \%$. Moreover, a high increase of radiance at 626 and $534 \mathrm{~nm}$ appears from cloudless to overcast conditions.

Figure 7 (bottom) presents the radiances under partially cloudy conditions. The black pixels correspond to saturated pixels due to a high radiance reaching the sensor. The cloudless regions are similar to the cloudless sky, showing the highest values in the shortest wavelength. The radiance is higher in the cloud regions than in the cloudless ones, which was also observed by Rossini and Krenzinger (2007). In fact, individual clouds increase the radiance up to saturate 


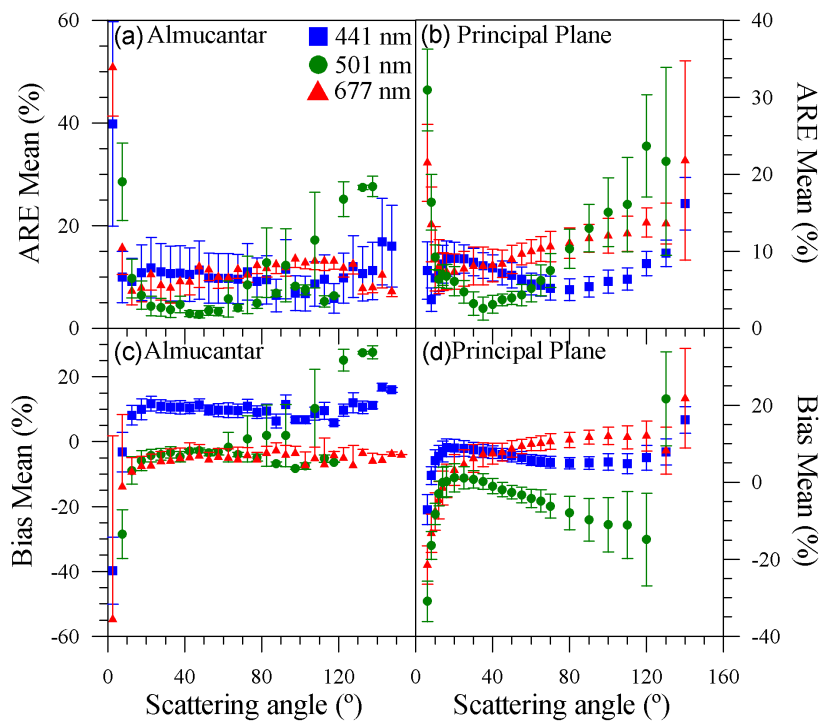

Fig. 6. Mean of the absolute relative error (ARE; a, b) and bias (c, d) between sky radiance retrieved by camera and measured by CIMEL for $677 \mathrm{~nm}, 501 \mathrm{~nm}$, and $441 \mathrm{~nm}$ as a function of the scattering angle. Left panels represent almucantar, and right panels are principal planes. The error bars represent the standard deviation, of which only half (up or down) is included for $677 \mathrm{~nm}$ (almucantar) due to the high values near to the Sun.

the pixels. Therefore, individual clouds increase the diffuse radiation reaching the Earth's surface. The coefficients of variation are higher under this condition than in the two before and it increases with the wavelength, being the mean of the radiance ( \pm standard deviation) using all pixels: 50 $( \pm 30), 60( \pm 30)$ and $90( \pm 40) \mathrm{m} \mathrm{W} \mathrm{m}^{-2} \mathrm{~nm}^{-1} \mathrm{sr}^{-1}$ for the red, green and blue channel, respectively. The highest deviation is caused by the differences between cloudless and cloud cover pixels. The blue channel shows a similar mean value in the cloudless and overcast conditions, which, due to its wavelength, is more affected by molecular scattering and, therefore, diffuse radiation is high also under cloudless conditions. However, clouds strongly increase the higher wavelengths.

Finally, 120 images (40 for each condition) were selected and analyzed for each sky condition. The mean radiance per solid angle and its standard deviation were calculated for each image. The average of the mean radiance and its standard deviation for the 40 cloudless images were $34( \pm 24), 55$ $( \pm 29)$ and $89( \pm 40) \mathrm{m} \mathrm{W} \mathrm{m}^{-2} \mathrm{~nm}^{-1} \mathrm{sr}^{-1}$ for the 626,534 and $464 \mathrm{~nm}$ wavelengths, respectively, showing similar results as in the cloudless images of Fig. 7. In the case of overcast skies, the average radiances were $63( \pm 14), 70( \pm 16)$ and $80( \pm 18)$ $\mathrm{m} \mathrm{W} \mathrm{m}{ }^{-2} \mathrm{~nm}^{-1} \mathrm{sr}^{-1}$ for the red, green and blue channel, respectively. Additionally, $73( \pm 35), 81( \pm 29)$ and $119( \pm 40)$ $\mathrm{m} \mathrm{W} \mathrm{m}{ }^{-2} \mathrm{~nm}^{-1} \mathrm{sr}^{-1}$ were the average values of the radiance mean and standard deviation of the 40 partially cloudless images for the 626, 534 and $464 \mathrm{~nm}$ wavelengths. These results
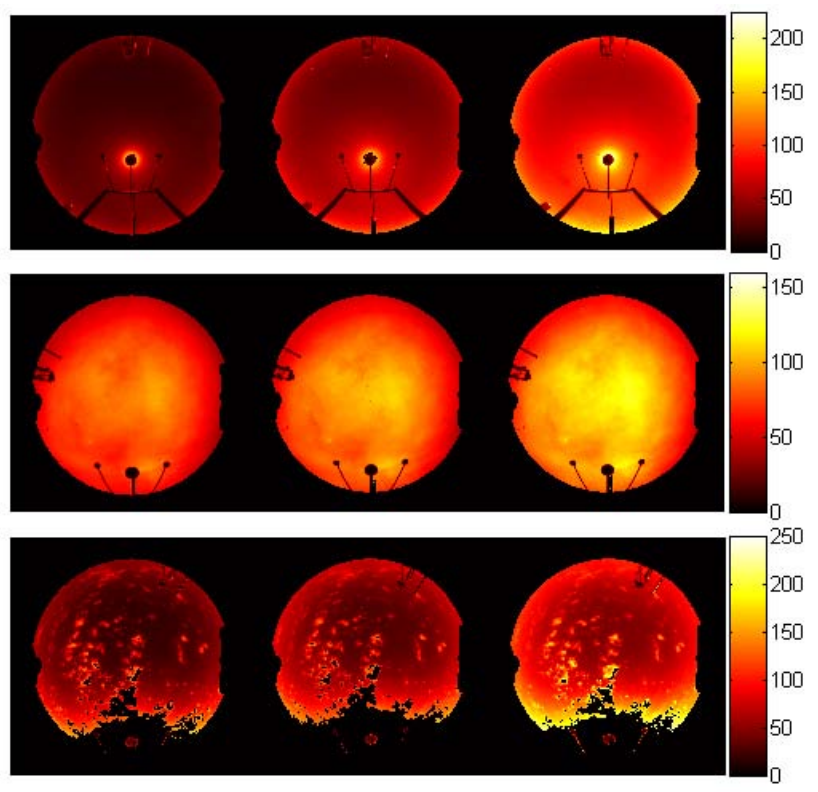

Fig. 7. Sky radiance (in $\mathrm{mW} \mathrm{m}^{-2} \mathrm{~nm}^{-1} \mathrm{sr}^{-1}$ ) at $626 \mathrm{~nm}$ (left), $534 \mathrm{~nm}$ (centre) and $464 \mathrm{~nm}$ (right) for top: a cloudless sky (8 July 2011, 13:15 UTC), middle: an obscured overcast sky (23 January 2011, 10:35 UTC), and bottom: a partially cloudy sky (7 March 2011, 16:15 UTC). Black regions represent the zenith angles higher than $80^{\circ}$, the two pyranometers installed near the camera, and the saturated pixels. Figure 2 helps to discern saturated (white) and lowradiance (black) pixels.

are in agreement with all conclusions obtained from Fig. 7, where the coefficient of variation increases with the wavelength except for overcast skies when the coefficient of variation is constant and close to $20 \%$.

\section{Conclusions}

Some important conclusions may be drawn from this work. The radiative transfer model UVSPEC estimates radiance values, under cloudless sky, similar to those recorded with a sunphotometer, obtaining the worst agreement between modelled and measured radiances near to the Sun. The mean differences between the modelled and measured sky radiances are lower than $20 \%$ for all scattering angles when the median is considered. Thus, UVSPEC model can be used to estimate cloudless sky radiances if some inputs, such as aerosol scattering phase function, are taken into account.

The obtained calibration matrices, which convert raw signal in physical radiance, do not show significant dependence on SZA, and the variability of their coefficients along 5 months is low, being the coefficient of variation lower than $10 \%$ for the $99 \%$ of the pixels. The mean differences between the radiance estimated with the camera and that measured with the CIMEL are lower than $15 \%$ except for high 
scattering angles and close to the Sun, showing the radiance at $464 \mathrm{~nm}$ the lowest differences in these angles.

The radiance under overcast conditions presents the highest homogeneity, while the largest variability in the radiance values corresponds to the partially cloudy conditions. Individual clouds increase the sky radiance at the higher wavelengths, and the horizon brightening under cloudless conditions changes to horizon dimming when the sky is obscured overcast.

Finally, in future works, other analyses of sky radiances might be developed, e.g. the use of radiances for the retrieval of cloud properties, and a global study of sky radiances under different sky conditions. The retrieval of aerosol properties using camera radiance information could be an option, but the radiance error given by the camera is too high for this purpose, and the camera wavelengths are not appropriated to obtain aerosol properties in the course mode. On the other hand, some aerosol optical properties such as AOD, $\alpha$ and $\beta$ could be calculated from sky camera radiances. The authors encourage researchers and groups with available camera system to apply and use the proposed method to obtain sky radiance from sky images, because only radiative transfer modelling is needed to derive the calibration matrices.

Acknowledgements. The authors gratefully acknowledge the financial support extended by the Spanish Innovation and Science Ministry for the projects: CGL2011-25363 and CGL2010-12140E. Roberto Román thanks Valladolid University for the support to research short stays and for the PIF-UVa grants for $\mathrm{PhD}$ students. This work was also partially supported by the Andalusian Regional Government through projects P08-RNM-3568 and P10-RNM-6299, the Spanish Ministry of Science and Technology through projects CGL2010-18782 and CSD2007-00067, and by the European Union through ACTRIS project (EU INFRA2010-1.1.16-262254). The Remote Sensing Technology Institute (IMF) at the German Aerospace Centre (DLR) of GOME and GOME-2 instruments and the National Aeronautics and Space Administration (NASA) of OMI are also acknowledged for making available the ozone data required for this study.

Edited by: P. Stammes

\section{References}

Alados, I., Olmo, F. J., Foyo-Moreno, I., Alados-Arboledas, L. Estimation of photosynthetically active radiation under cloudy conditions, Agr. Forest Meteorol., 102, 39-50, 2000.

Alados-Arboledas, L., Alados I., Foyo-Moreno I., Alcántara A, and Olmo, F. J.: The influence of clouds on surface UV erythemal irradiance, Atmos. Res., 66, 273-290, 2003.

Antón, M., López, M., Vilaplana, J. M., Kroon, M., McPeters, R., Bañón, M., and Serrano, A.: Validation of OMI-TOMS and OMIDOAS total ozone column using five Brewer spectroradiometers at the Iberian peninsula, J. Geophys. Res., 114, D14307, doi:10.1029/2009JD012003, 2009a.
Antón, M., Loyola, D., López, M., Vilaplana, J. M., Bañón, M., Zimmer, W., and Serrano, A.: Comparison of GOME2/MetOp total ozone data with Brewer spectroradiometer data over the Iberian Peninsula, Ann. Geophys., 27, 1377-1386, doi:10.5194/angeo-27-1377-2009, 2009 b.

Antón, M., Gil, J. E., Cazorla, A., Fernández-Gálvez, J., FoyoMoreno, I., Olmo, F. J., and Alados-Arboledas, L.: Short-term variability of experimental ultraviolet and total solar irradiance in Southeastern Spain, Atmos. Environ., 45, 4815-4821, doi:10.1016/j.atmosenv.2011.06.020, 2011a.

Antón, M., Gil, J. E., Cazorla, A., Fernández-Gálvez, J., Vilaplana, J. M., Olmo, F. J., and Alados-Arboledas, L.: Influence of the calibration on experimental UV index at a midlatitude site, Granada (Spain), Atmos. Meas. Tech., 4, 499-507, doi:10.5194/amt-4499-2011, 2011 b.

Bilbao, J., Román, R., de Miguel, A., and Mateos, D.: Long-term solar erythemal UV irradiance data reconstruction in Spain using a semiempirical method, J. Geophys. Res., 116, D22211, doi:10.1029/2011JD015836, 2011.

Buras, R., Dowling, T., and Emde, C.: New secondary-scattering correction in DISORT with increased efficiency for forward scattering, J. Quant. Spectrosc. Ra., 112, 2028-2034, doi:10.1016/j.jqsrt.2011.03.019, 2011.

Cazorla, A.: Development of a sky imager for cloud classification and aerosol characterization, Ph.D. thesis, University of Granada, Spain, 2010.

Cazorla, A., Olmo, F. J. and Alados-Arboledas, L.: Using a Sky Imager for aerosol characterization, Atmos. Environ., 42, 27392745, doi:10.1016/j.atmosenv.2007.06.016, 2008a.

Cazorla, A., Olmo, F. J., and Alados-Arboledas, L.: Development of a sky imager for cloud cover assessment, Opt. Soc. Am. A., 25, 29-39, 2008b.

Cazorla, A., Shields, J. E., Karr, M. E., Olmo, F. J., Burden, A., and Alados-Arboledas, L.: Technical Note: Determination of aerosol optical properties by a calibrated sky imager, Atmos. Chem. Phys., 9, 6417-6427, doi:10.5194/acp-9-6417-2009, 2009.

De Miguel, A., Mateos, D., Bilbao, J., and Román, R.: Sensitivity analysis of ratio between ultraviolet and total shortwave solar radiation to cloudiness, ozone, aerosols and precipitable water, Atmos. Res., 102, 136-144, doi:10.1016/j.atmosres.2011.06.019, 2011a.

De Miguel, A., Román, R., Bilbao, J., and Mateos, D.: Evolution of erythemal and total shortwave solar radiation in Valladolid, Spain: Effects of atmospheric factors, J. Atmos. Sol-Terr. Phy., 73, 578-586, 2011b.

Dubovik, O. and King, M. D.: A flexible inversion algorithm for retrieval of aerosol optical properties from Sun and sky radiance measurements, J. Geophys. Res. Atmos., 105, 20673-20696, doi:10.1029/2000JD900282, 2000.

Dubovik, O., Sinyuk, A., Lapyonok, T., Holben, B. N., Mishchenko, M., Yang, P., Eck, T., Volten, H., Munoz, O., Veihelmann, B., Van Der Zande, W. J., Leon, J., Sorokin, M., and Slutsker, I: Application of spheroid models to account for aerosol particle nonsphericity in remote sensing of desert dust, J. Geophys. Res.Atmos., 111, D11208, doi:10.1029/2005JD006619, 2006.

Foyo-Moreno, I., Alados, I., Olmo, F. J., Vida, J., and AladosArboledas, L: On the use of a cloud modification factor for solar UV (290- $385 \mathrm{~nm}$ ) spectral range, Theor. Appl. Climatol., 68, 41-50, 2001. 
Grant, R. H. and Heisler, G. M.: Obscured overcast sky radiance distributions for ultraviolet and photosynthetically active radiation, J. Appl. Meteor., 36, 1336-1345, 1997.

Grant, R. H., Heisler, G. M., and Gao, W.: Clear sky radiance distributions in ultraviolet wavelength bands, Theor. Appl. Climatol., 56, 123-135, 1997a.

Grant, R. H., Heisler, G. M., and Gao, W.: Ultraviolet sky radiance distributions of translucent overcast skies, Theor. Appl. Climatol., 58, 129-139, 1997b.

Gueymard, C. A.: Interdisciplinary applications of a versatile spectral solar irradiance model: A review, Energy 30, 1551-1576, 2005.

Heinle, A., Macke, A., and Srivastav, A.: Automatic cloud classification of whole sky images, Atmos. Meas. Tech., 3, 557-567, doi:10.5194/amt-3-557-2010, 2010.

Holben, B. N., Eck, T. F., Slutsker, I., Tanré, D., Buis, J. P., Setzer, A., Vermote, E., Reagan, J. A., Kaufman, Y. J., Nakajima, T., Lavenu, F., Janlowiak, I., and Smirnov, A.: AERONET - A federated instrument network and data archive for aerosol characterization, Remote Sens. Environm., 66, 1-16, 1998.

Horváth, G., Barta, A., Gál, J., Suhai, B., and Haiman, O.: Groundbased full-sky imaging polarimetry of rapidly changing skies and its use for polarimetric cloud detection, Appl. Optics, 41, 543$559,2002$.

Kholopov, G. K.: Calculation of the effective wavelength of a measuring system, J. Appl. Spectrosc., 23, 1146-1147, doi:10.1007/BF00611771, 1975.

Kreuter, A., Zangerl, M., Schwarzmann, M., and Blumthaler, M.: All-sky imaging: a simple, versatile system for atmospheric research, Appl. Optics, 48, 1091-1097, 2009.

Long, C. M., Sabburg, J. M., Calbó, J., and Pagès, D.: Retrieving Cloud Characteristics from Ground-Based Daytime Color AllSky Images, J. Atmos. Ocean. Tech., 23, 633-652, 2006.

López-Álvarez, M., Hernández-Andrés, J., Romero, J., Olmo, F. J., Cazorla, A., and Alados-Arboledas, L.: Using a trichromatic CCD camera for spectral skylight estimation, Appl. Optics, 47, 31-38, 2008.

Lyamani, H., Olmo, F. J., and Alados-Arboledas, L.: Physical and optical properties of aerosols over an urban location in Spain: seasonal and diurnal variability, Atmos. Chem. Phys., 10, 239254, doi:10.5194/acp-10-239-2010, 2010.

Lyamani, H., Olmo, F. J., Foyo, I., and Alados-Arboledas, L.: Black carbon aerosols over an urban area in south-eastern Spain: Changes detected after the 2008 economic crisis, Atmos. Environ., 45, 6423-6432, doi:10.1016/j.atmosenv.2011.07.063, 2011.

Mannstein, H., Brömser, A., and Bugliaro, L.: Ground-based observations for the validation of contrails and cirrus detection in satellite imagery, Atmos. Meas. Tech., 3, 655-669, doi:10.5194/amt3-655-2010, 2010.

Mayer, B. and Kylling, A.: Technical note: The libRadtran software package for radiative transfer calculations - description and examples of use, Atmos. Chem. Phys., 5, 1855-1877, doi:10.5194/acp-5-1855-2005, 2005.
Nakajima, T. and Tanaka, M.: Algorithms for radiative intensity calculations in moderately thick atmospheres using a truncation approximation, J. Quant. Spectrosc. Ra., 40, 51-69, 1988.

Nakajima, T., Tonna, G., Rao, R., Boi, P., Kaufman, Y., and Holben, B.: Use of sky brightness measurements from ground for remote sensing of particulate dispersion, Appl. Optics, 35, 2672-2686, 1996.

Olmo, F. J., Cazorla, A., Alados-Arboledas, L., López-Álvarez, M., Hernández-Andrés, J., and Romero, J.: Retrieval of the optical depth using an all-sky camera, Appl. Optics, 47, 182-189, 2008a.

Olmo, F. J., Quirantes, A., Lara, V., Lyamani, H., and AladosArboledas, L.: Aerosol optical properties assessed by an inversion method using the solar principal plane for non-spherical particles, J Quant. Spectrosc. Ra., 109, 1504-1516, 2008 b.

Piacentini, R. D., Salum, G. M., Fraidenraich, N., and Tiba, C.: Extreme total solar irradiance due to cloud enhancement at sea level of the NE Atlantic coast of Brazil, Renewable Energy, 36, 409412, 2010.

Rossini, E. G. and Krenzinger, A.: Maps of sky relative radiance and luminance distributions acquired with a monochromatic CCD camera, Sol. Energy, 81, 1323-1332, doi:10.1016/j.solener.2007.06.013, 2007.

Shettle, E. P.: Models of aerosols, clouds and precipitation for atmospheric propagation studies, in AGARD Conference Proceedings No. 454, Atmospheric propagation in the uv, visible, IR and mm-region and related system aspects, Advisory Group for Aerospace Research Development (AGARD), Brussels, Belgium, 1989.

Stamnes, K., Tsay, S.-C., Wiscombe, W., and Laszlo, I.: DISORT, a General-Purpose Fortran Program for Discrete-Ordinate-Method Radiative Transfer in Scattering and Emitting Layered Media: Documentation of Methodology, Tech. rep., Dept. of Physics and Engineering Physics, Stevens Institute of Technology, Hoboken, NJ 07030, 2000.

Vida, J., Foyo-Moreno, I., and Alados-Arboledas, L.: The European Community Cloudless Sky Radiance Model. An Evaluation by Means of the Skyscan'834 Data Set, Theor. Appl. Climatol., 63, 141-147, 1999.

Voss, K. J. and Liu, Y.: Polarized radiance distribution measurements of skylight. I. System description and characterization, Appl. Optics, 36, 6083-6094, 1997.

Voss, K. J. and Zibordi, G.: Radiometric and geometric calibration of a visible spectral electro-optic "fisheye" camera radiance distribution system, J. Atmos. Ocean. Tech., 6, 652-662, 1989.

Weihs, P., Webb, A. R., Hutchinson, S. J., and Middleton, G. W.: Measurements of the diffuse UV sky radiance during broken cloud conditions, J. Geophys. Res., 105, 4937-4944, 2000.

Wuttke, S. and Seckmeyer, G.: Spectral radiance and sky luminance in Antarctica: a case study, Theor. Appl. Climatol., 85, 131-148, doi:10.1007/s00704-005-0188-2, 2006.

Zibordi, G. and Voss, K. J.: Geometrical and spectral distribution of sky radiance: Comparison between simulations and field measurements, Remote Sens. Environ., 27, 343-358, 1989. 